\title{
Numerical Model and Experimental Validation of the Hydrodynamics in an Industrial-Scale Sewage Sludge Bubbling Fluidized Bed Incinerator
}

\author{
Embarek Belhadj ${ }^{1, *}$, William Nimmo ${ }^{2}$, Hubert Roth $^{1}$, Mohamed Pourkashanian ${ }^{2}$ \\ ${ }^{l}$ (Department of Electrical Engineering and Computer Science, Institute of Automatic Control Engineering, \\ University of Siegen, Siegen, Germany \\ ${ }^{2}$ (Department of Mechanical Engineering, The University of Sheffield, Sheffield, UK, S1O 2TN)
}

\begin{abstract}
This paper describes a development of a numerical model and experimental validation of the hydrodynamics in industrial-scale sewage sludge bubbling fluidized bed incinerator. The numerical model and simulations are performed using commercial CFD software package ANSYS Fluent 14.5. The complex geometry of the developed numerical model represents the actual industrial-scale bubbling fluidized bed combustor. The gassolid flow behaviour inside the bed was described using the Eulerian-Eulerian multiphase model. The momentum exchange coefficients between the gas phase and solid particles were described by the Syamlal and O'Brien drag model equations. The CFD transient simulations were run for 350 seconds at the optimum operating conditions of the used fluidized bed with bed temperature of $850^{\circ} \mathrm{C}$. The experiments were carried out using quartz sand with three different particle sizes having a diameters ranging from $0.5 \mathrm{~mm}$ to $1.5 \mathrm{~mm}$ and a density of $2650 \mathrm{~kg} / \mathrm{m}^{3}$. The industrial-scale furnace was filled with bed material to a bed height of $0.85 \mathrm{~m}$. The same operating parameters have been applied for both experimental and numerical studies. The hydrodynamics of the gas-solid industrial-scale bubbling fluidized bed at operating conditions are investigated in the CFD numerical model and simulations of this three-dimensional (3D) complex geometry. To estimate the prediction quality of the simulations based on the developed numerical model, the minimum fluidization gas velocity and pressure drop results obtained from the CFD simulations are validated with the experimental measurements. The generated simulation results of the pressure drop and minimum fluidization gas velocity of the industrial-scale sewage sludge incinerator based the Eulerian-Eulerian method and Syamlal and O'Brien drag model are in good agreement with the experimental measured data.
\end{abstract}

Keywords: Fluidized bed, Gas-solid hydrodynamics, CFD simulation, CFD Multiphase model, Sewage sludge incineration

\section{INTRODUCTION}

The municipal wastewater treatment plants in Germany generate approximately two million tons of dry sewage sludge every year. The thermal treatment of sewage sludge has been increased in the period from 2004 to 2011 , from $31.5 \%$ to more than $54 \%$. Currently more than $25 \%$ of this generated sewage sludge is incinerated in mono-incineration plants, which is mainly performed in bubbling fluidized bed incinerators $[1,2]$.

In the sewage sludge bubbling fluidized bed combustion plants, the sewage sludge fuel is injected into a combustion chamber and combusted, when the fuel particles come in contact with the suspended hot quartz sand particles as inert material and combustion air. The generated heat energy from the combustion process of the sewage sludge is absorbed by the quartz sand layer. The absorption of this thermal energy by the bed mass during the combustion results in a uniform temperature distribution throughout the bed, so that each particle of the inert material has the same temperature to avoid the formation of temperature peaks inside the fluidized bed. The combustion temperature of about $850^{\circ} \mathrm{C}$ is controlled by the using of auxiliary firing with sewage gas as well as natural gas. The inert material is fluidized by the hot air coming from the recuperator which is preheated by the flue gas stream leaving the incinerator. The bed high of the fluidized bed material can be adjusted and limited by the control of pressure drop of the inert material and the fluidizing air flow rate. A uniform and stable fluidization of the bed material is crucial for insuring a uniform temperature distribution and an efficient and complete combustion with minimal pollutant formation, especially by the combustion of some problematic fuels. Therefore, the first measure for avoiding an inhomogeneous temperature distribution and an incomplete combustion is the pressure drop of the inert material, and thus sewage sludge fuel can only introduced and the combustion take place if a uniform fluidization of bed material is available. Due to the thermal mass of the inert material, also 
fuels with high moisture content and calorific value can be effectively used in bubbling fluidized bed combustor. The bed particles act as a moving thermal energy accumulator and match the fluctuations in fuel properties. Therefore, the fluidized bed technology is the most widely used in combustion plants for the thermal treatment of problematic waste. The main advantages of this combustion technology lie in its excellent mixing, the rapid heat transfer and the efficient and lowemission combustion. An additional advantage of this relatively new technology is the ability to burn various fuels in the same unit as well as the staged air and the low combustion temperature which keeps the formation of thermal $\left(\mathrm{NO}_{\mathrm{X}}\right)$ reduced to very low levels. Due to all this fluidized bed advantages, fluidized bed technological process found its use in various applications, especially in the energy and chemical industries, as well as in the thermal treatment of municipal solid waste and sewage sludge. According to the various applications of the fluidized bed system, the use of this technology has enormously increased.

In operation, the fluidizing air is injected into the combustion chamber of the incinerator through the grate at the bottom of the bed and used as both fluidization and combustion air. Because this primary air is responsible for the fluidization of the inert material the bed, the superficial air velocity should be at least equal with the minimum fluidization gas velocity of the bubbling fluidized bed. In addition, the primary air velocity increases with increasing the air temperature. Furthermore the air flow rate has to be not much higher than required to maintain a stable fluidization of sand particles to insure an optimum process operation. A good mixing of hot bed material ensure a good contact between combustion air and fuel particles and results in homogeneous temperature distribution so that only low excess air level for an efficient and complete combustion is required as in other conventional incineration processes. This lower excess air leads to reduce the flue gas volume and therefore to reduce the operating costs by the gas cleaning process as well as increasing the efficiency of the whole plant. Therefore, a study of the hydrodynamic behaviour study of the bubbling fluidized bed combustor is necessary to improve the incineration processes and reduce the pollutant emissions. In addition to the experimental studies on gas-solid multiphase flow in bubbling fluidized bed incinerators, several universities and research centres worldwide are involved in investigating the hydrodynamic behaviour of bed material inside the fluidized beds, especially the minimum fluidization gas velocity and the pressure drop of the distributor plate generated by the inert material using Computational Fluid Dynamics (CFD) program, so that this method is state of the art. This fluid dynamics software has been developed specifically for the modelling and simulation of the complex flow processes. The CFD has proven its efficiency and becomes an essential tool for the analysis and optimisation of combustion systems as well as in many processes. Computational Fluid Dynamics is the most commonly used numerical method to investigate the multiphase flow. The use of CFD simulation for fluidized bed reduces the need to a very expensive as well as time consuming experimentation for the process design and optimization [3].

There are generally two different approaches for the numerical study of the gas-solid multiphase flow with CFD (Computational Fluid Dynamics) applied and reported in the literature, the Euler-Euler and Euler-Lagrange method [4, 5]. In the Euler-Euler method, both phases the continuous gas phase and solid particle phase are calculated as a continuum in a fixed volume control. In contrast to the first method, in the Euler-Lagrange method, the gas phase is treated as continuum, and on the other hand the solid particle phase is calculated by the Newtonian equations of motion for each individual particle in the bubbling fluidized bed. The numerical simulation with the Euler-Lagrange method, in which means that an equation of motion is calculated for each solid particle is computationally very time consuming, especially for high number of particles in a large-scale industrial fluidized beds [3].

Numerous drag models have been developed and applied in recent years to describe the interactions between the gas and the solid phase inside the fluidized bed system. The drag models of Syamlal and O'Brien, Wen and Yu and Gidaspow are the most used models in the investigation of the hydrodynamic behaviour in gas-solid bubbling fluidized beds [5-7]. Unfortunately, there are only a limited works introduced in the literature, where researchers applied both experimental and numerical investigations to validate the numerical results.

Taghipour et al. [9] have studied the gas-solid hydrodynamics in two-dimensional (2D) fluidized bed incinerator based on Wen and Yu, Gidaspow and Syamlal and O'Brien drag models. They found that the generated pressure drop results at higher gas velocity than the minimum fluidization gas velocity based on Gidaspow and Syamlal and O'Brien drag models are in good agreement with the experimental measured data.

Hamzehei, M. and Rahimzadeh, H. [10-14] have compared the bed expansion and pressure drop results obtained from the CFD simulations based on the Syamlal and O'Brien drag model with the experimental measurements. They found that the numerical model generated results are in good agreement with the experimental Measurements. 
They concluded also that the Syamlal and O'Brien drag functions are able to forecast the gas-solid hydrodynamics of a fluidized bed correctly.

Ramesh and Raajenthiren, [15] have studied the hydrodynamics of the gas-solid fluidized bed based on the Gidaspow, Arastoopour, and Syamlal and O'Brien drag models, and found that the Syamlal and O'Brien drag model predicts better hydrodynamic results, and these results are also in good agreement with the experimental measured data compared to the other drag models.

Almuttahar [16] has also compared the Gidaspow, Syamlal and O'Brien and Arastoopour drag models to predict better gas-solid hydrodynamic results inside the bed based on the minimum fluidization gas velocity, and found the modified drag model of Syamlal and O'Brien to provide better performance compared to Arastoopour and Gidaspow models.

Esmaili and Mahinpey [17] have investigated the generated simulation results from eleven drag models based on the minimum fluidization gas velocity, and found that Syamlal and O'Brien drag model predicts better hydrodynamics. Syamlal and O'Brien drag model is also found to provide higher forecast accuracy of the minimum fluidization gas velocity compared to those drag models. In addition, they also found that simulations based on 3D numerical models provide better predictions compared to those applied in 2D models. Wang et al. [18] found also that 3D predicts much better simulation results than $2 \mathrm{D}$ domains, and the 3D obtained simulation results are in best agreement with the experimental measured data.

Schreiber et al. [19] found that simulations based on 3D domains give better agreements with the experimental measurements, but on the other hand computationally very expensive and require a large amount of computer resources.

The main issues in validating threedimensional CFD simulations with experimental measurements are the computational resources required and the computation time needed to predict detailed hydrodynamic results of a bubbling fluidized bed combustor, especially for industrialscale systems. The most of the CFD numerical investigations on hydrodynamic behaviour in bubbling fluidized bed were applied in twodimensional models of a laboratory-scale fluidized bed. Therefore, the purpose of this work is to fill this gap by investigating the hydrodynamic behaviour of the inert material in a threedimensional numerical model of an industrial-scale bubbling fluidized bed combustor, and validating the obtained numerical simulation results against the experimental measurements.

The objective of this combined numerical and experimental investigations applied at the industrial-scale bubbling fluidized bed combustor is to evaluate the accuracy of the two basic operating parameters that effect the combustion processes, which are the minimum fluidization gas velocity and pressure drop of the inert material. To determine the impact of particle sizes and superficial gas velocity on the fluidization behaviour of bed material inside the bubbling fluidized bed as well as the pressure drop generated by the bed mass, the obtained CFD simulation results from the developed numerical model using the Eulerian-Eulerian multiphase approach with the Syamlal and O'Brien drag model are validated by comparing these predicted results with the experimental measurements of the rig, and finally, to check if the used drag model predicts correctly the fluidization behaviour of the applied industrial-scale bubbling fluidized bed.

\section{THE CFD MODEL AND SIMULATION}

The The interactions between the gas and quartz sand particles were studied in the modelled industrial-scale bubbling fluidized bed. The complex geometry of the developed three-dimensional numerical model is similar to the industrial-scale combustor. The model was created in SolidWorks, the meshing was developed in ICEM CFD software. The three-dimensional numerical domain of the rig was meshed with structured hexahedral grids of approximately 683000 cells, 1520000 faces and 240000 nodes. The used complex geometry model of the gas-solid industrial-scale bubbling fluidized bed is shown in figure 1.

Based on the Eulerian-Eulerian method, the commercial Computational Fluid Dynamics code FLUENT 14.5 is applied to simulate the gas-solid multiphase flow. In this multiphase method, both phases are considered mathematically as interpenetrating continua. The Syamlal and O'Brien drag functions are applied to calculate the gas-solid exchange coefficients.

The inside dimensions of the cylindrical industrial-scale bubbling fluidized bed combustor are a bed diameter of $3.44 \mathrm{~m}$, which gives an area of about $9.3 \mathrm{~m}^{2}$, and a bed height, including freeboard of $8.8 \mathrm{~m}$. Three different quartz sand particle diameters ranging from $0.5 \mathrm{~mm}$ to $1.5 \mathrm{~mm}$ with a density of $2650 \mathrm{~kg} / \mathrm{m} 3$ were used. These values are consistent with those of the experimental industrialscale bubbling fluidized bed. The same operating conditions were applied for all the numerical investigations performed with varying only the inlet gas velocity and the sand particle sizes. The inlet gas velocities were set as $0.8 \mathrm{~m} / \mathrm{s}, 1.0 \mathrm{~m} / \mathrm{s}, 1.35 \mathrm{~m} / \mathrm{s}$, and $1.5 \mathrm{~m} / \mathrm{s}$. The CFD numerical simulations were running in transient mode for a simulation time of 350 seconds. The CFD numerical model was developed to analyse how the sand particle sizes and the superficial inlet air velocity influence the 
fluidization behaviour of the industrial-scale bubbling fluidized bed combustor, particularly the generated pressure drop across the distributor plate to get the useful values for the basic operating parameters, and finally to determine the efficient parameters for the bubbling flow regime inside the bed.

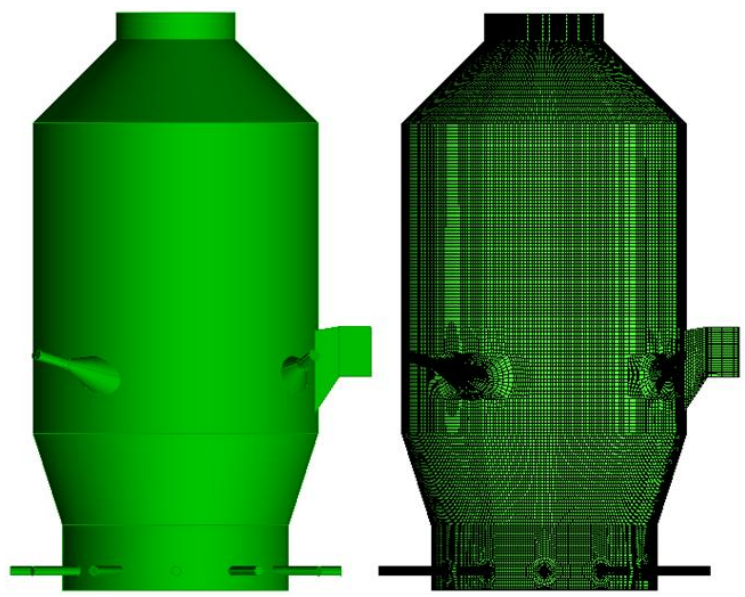

Fig. 1: The complete geometry and numerical mesh model of the industrial-scale bubbling fluidized bed

To estimate the prediction quality of the developed numerical model, the minimum fluidization gas velocity and pressure drop results obtained from the CFD simulations are validated with the experimental measurements.

\section{○ The Euler-Euler approach equations}

The numerical model proposed in this work to describe the gas-solid flow behaviour in the industrial-scale bubbling fluidized bed combustor is based on the multiphase Eulerian-Eulerian method. This multiphase approach is widely used to forecast the hydrodynamics in a gas-solid fluidized beds. The Eulerian-Eulerian multiphase model treats both gas and particle phase as interpenetrating continua. The flow of this multiphase model is given by the continuity and momentum equations. The gas and solid phase momentum and continuity equations are given for each phase [8, 20, 23].

The gas and solid phase continuity equations can be written as follows:

$$
\begin{aligned}
& \frac{\partial}{\partial t}\left(\varepsilon_{g} \rho_{g}\right)+\nabla \cdot\left(\varepsilon_{g} \rho_{g} v_{g}\right)=0 \\
& \frac{\partial}{\partial t}\left(\varepsilon_{g} \rho_{g}\right)+\nabla \cdot\left(\varepsilon_{s} \rho_{s} v_{s}\right)=0
\end{aligned}
$$

Where $\rho_{g}$ and $\rho_{s}$ are the gas and solid phase densities, $v_{g}$ and $v_{s}$ are the gas and solid phase velocity vectors.
Subscripts (g) and (s) denote the gas and solid phases, where $\varepsilon_{g}$ and $\varepsilon_{s}$ denote the gas and solid volume fractions, which is occupied by the total volume satisfying the condition that all the volume fractions sum to 1 .

$\varepsilon_{g}+\varepsilon_{s}=1$

The gas and solid phase momentum balance equations can be written as follows:

$$
\begin{aligned}
& \frac{\partial}{\partial t}\left(\varepsilon_{g} \rho_{g} v_{g}\right)+\nabla \cdot\left(\varepsilon_{g} \rho_{g} v_{g} v_{g}\right)=-\varepsilon_{g} \nabla_{p} \\
& +\nabla \cdot \overline{\overline{\tau_{g}}}+\varepsilon_{g} \rho_{g} g+K_{s g}\left(v_{s}-v_{g}\right) \\
& \frac{\partial}{\partial t}\left(\varepsilon_{s} \rho_{s} v_{s}\right)+\nabla \cdot\left(\varepsilon_{s} \rho_{s} v_{s} v_{s}\right)=-\varepsilon_{s} \nabla_{p}-\nabla_{p_{s}} \\
& +\nabla \cdot \overline{\overline{\tau_{s}}}+\varepsilon_{s} \rho_{s} g+K_{g s}\left(v_{g}-v_{s}\right)
\end{aligned}
$$

Subscript $P$ denote the pressure shared by all gas and solid phases, where $P_{s}$ denote the pressure of solid phase, $\overline{\overline{\tau_{s}}}$ denote the stress tensor, g denote the gravity and $K_{s g}=K_{g s}$ are the gas-solid exchange coefficients.

\section{- The drag model}

The momentum exchange coefficient which describes the drag force between the gas phase and solid particles, plays an essential role in the gas-solid multiphase flow processes. Different drag models are developed, investigated and reported in the literature to predict the interphase momentum exchange $K_{g s}$ in fluidized bed combustors based on kinetic theory of granular flow (KTGF) [6].

The three popular and most widely used drag models are Gidaspow, Wen-Yu and Syamlal and O'Brien model [16, 20-22]. Syamlal and O'Brien drag model is found to predict better hydrodynamic results compared to other models, and therefore more suitable for investigating the hydrodynamics of gas-solid bubbling fluidized bed combustors $[10,16]$.

For this reason, the Syamlal and O'Brien drag equations have been used in this investigation to calculate the momentum exchange between the gas phase and solid particles inside the fluidized bed. This drag model functions are based on the measurement of the terminal velocities of solid particles inside the fluidized bed combustors, with 
correlations that are a functions of the relative Reynolds number and volume fraction [10-12, 22].

The gas phase and solid particles exchange coefficient can be written as follows:

$K_{g s}=\frac{3 \times \varepsilon_{g} \times \varepsilon_{g} \times \rho_{g}}{4 \times v_{r, s}{ }^{2} \times d_{s}} \times C_{D} \times\left(\frac{R e_{s}}{v_{r, s}}\right) \times\left|v_{g}-v_{s}\right|$

Where the drag function is given by:

$C_{D}=\left(0.63+\frac{R e_{s}}{\sqrt{\frac{R e_{s}}{v_{r_{\mathrm{a}} s}}}}\right)^{2}$

and $v_{r, s}$ is the solid particles terminal velocity correlation:

$v_{r, s}=0.5 A-0.03 R e_{s}+$

$0.5 \times \sqrt{\left(0.06 R e_{g}\right)^{2}+0.12 R e_{g}(2 B-A)+A^{2}}$

with $A=\varepsilon_{g}{ }^{4,14}$

and $B=\left\{\begin{array}{c}0.8 \cdot \varepsilon_{g}^{1.28} \text { for } \varepsilon_{g} \leq 0.85 \\ \varepsilon_{g}^{2.65} \text { for } \varepsilon_{g}>0.85\end{array}\right.$

The solid particles relative Reynolds number is defined as:

$R e_{s}=\frac{\rho_{g} \cdot d_{s} \cdot\left|v_{g}-v_{s}\right|}{\mu_{g}}$

where $d_{s}$ denote the solid particle diameter and $\mu_{g}$ the gas phase dynamic viscosity.

\section{- The minimum fluidization gas velocity and pressure drop}

In the bubbling fluidized bed combustion, the flow rate of the combustion air plays important roles in the combustion processes, which primarily provide an air sitting cushion for the solid particles across the distributor plate as well as a uniform mixing of the inert material to ensure an efficient and complete combustion of sewage sludge.

The good mixing of bed material results in a uniform temperature distribution inside the fluidized bed as well as an efficient and complete combustion of the sewage sludge. In the bubbling fluidized bed incineration process, the solid particles expansion inside the furnace is continuously monitored by measuring the generated pressure drop across the distributor, and limited by the control of the fluidization gas velocity. Therefore, the minimum fluidization gas velocity and pressure drop are the fundamental process parameters of the bubbling fluidized bed, and thus the most investigated parameters to characterize the fluidization of inert material inside the incinerator. Knowledge of the minimum fluidisation gas velocity needed to fluidize the inert material and bed pressure drop are necessary to design, operate and optimize the combustion process in bubbling fluidized bed. A stable fluidization of the inert material is required to achieve an optimal and effective combustion process inside the bed. The fluidization gas velocity is calculated by dividing the measured gas flow rate by the cross-sectional area of the used industrial-scale furnace. The pressure drop of the gas-solid bubbling fluidized bed is the difference between the measured pressure values below and above the inert material in the freeboard area [24, 25].

At the minimum fluidization velocity, the fluidized bed pressure drop generated from bed material is expected to have a value equal to the weight of the inert material per unit area of the distributor, and thus the pressure drop across the bed drop $\Delta p$ is defined as [26-28]:

$$
\Delta p=\left(1-\varepsilon_{m f}\right) \times\left(\rho_{s}-\rho_{g}\right) \cdot g \times h_{m f}
$$

Where $g$ denote the gravity, $\varepsilon_{m f}$ the fluid phase volume fraction at the minimum fluidization gas velocity and $h_{m f}$ denote the height of the inert material.

The transition from the fixed bed to fluidization regime in the bubbling fluidized bed is determined by controlling the combustion air flow rate, and attained by reaching the minimum fluidization gas velocity $U_{m f}$. This transition occurs depends on inert material particle sizes and density [7, 31].

Ergun's equation of $U_{m f}$ for fine particles is defined as:

$U_{m f}=\frac{d_{g}{ }^{2} \cdot\left(\rho_{s}-\rho_{g}\right) \cdot g}{1650-\mu_{g}}$ for $R e_{s}<0.85$

Ergun's equation of $U_{m f}$ for large particles is defined as:

$$
U_{m f}^{2}=\frac{d_{s} \cdot\left(\rho_{s}-\rho_{g}\right) \cdot g}{24.5 \cdot \mu_{g}} \text { for } R e_{s}>1000
$$

At the minimum fluidization gas velocity $U_{m f}$ of the bubbling fluidized bed incinerator, the Reynolds number $R e_{m f}$ is defined as [28-30]:

$R e_{m f}=\frac{\rho_{g} \cdot d_{g} \cdot U_{m f}}{\mu_{g}}$ 


\section{THE EXPERIMENTAL TEST INDUSTRIAL-SCALE BUBBLING FLUIDIZED BED}

The experimental work was performed in an industrial sized cylindrical fluidized bed incinerator, with an inside furnace diameter of 3.44 $\mathrm{m}$ and $\mathrm{a}$ bed height of $8.8 \mathrm{~m}$. These dimensions enable incineration of about $1400 \mathrm{~kg} / \mathrm{h}$ of dried sewage sludge, depending on moisture content and plant operating conditions. The fluidized bed incinerator consists of the windbox, the conical fluidized bed cross-sectional area with the fluidizing nozzles and sand as inert material, the cylindrical freeboard, and the upper part with the flue gas outlet. A Screen capture of the industrial-scale bubbling fluidized incinerator used in this study is shown in figure 2.

The industrial-scale furnace was filled with mixed quartz sand as inert material to a bed height of $0.85 \mathrm{~m}$ with particle sizes ranging from $0.5 \mathrm{~mm}$ to $1.5 \mathrm{~mm}$ in diameter and a density of $2650 \mathrm{~kg} / \mathrm{m}^{3}$. The same conditions are used for the present CFDsimulations.

The preheated fluidizing air is injected into the sewage sludge combustion chamber via a multiple air nozzles, which are positioned uniformly above the primary air distributor plate of this industrial-scale bubbling fluidized bed incinerator. To maintain the furnace of this industrial-scale rig at the operating temperature of about $850^{\circ} \mathrm{C}$, the preheated primary air from the recuperator by the flue gas leaving the incinerator to a temperature of approx. $650^{\circ} \mathrm{C}$ is further increased by using a sewage/natural gas burner installed in the windbox at the bottom of the combustor to a combustion air temperature ranging from $800^{\circ} \mathrm{C}$ to $850^{\circ} \mathrm{C}$.

All temperatures measured by the thermocouples located at different levels in the freeboard of the furnace are between $850^{\circ} \mathrm{C}$ and $920^{\circ} \mathrm{C}$. The pressure drop of the bed material across the distributor plate is controlled by regulating both the volume flow rate of the primary air and the windbox temperature. In the process, the combustion temperatures are controlled by regulating the volume flow rate of the auxiliary fuel depending on the moisture content of the sewage sludge.
This combustion unit is also equipped with a gas cleaning system and gas measurement devices. After leaving the combustor, the resulting combustion flue gas which is produced during the sewage sludge incineration process is cleaned by a multistage flue gas cleaning units consisting of electrostatic precipitator, spray cooler, back circulator and bag filter. The cleaned flue gas exits the bag filter through the chimney into the atmosphere.

All the essential process parameters of the industrial-scale furnace such as the oxygen concentration, combustion temperatures and pressures are measured continuously with authorized measurement devices and stored in a local database. The measurement of emissions according to the 17.BImSchV (German Federal Emission Control Ordinance) are registered and analysed continuously by the emission computer. This industrial-scale sewage sludge fired furnace works in the bubbling fluidization condition. Therefore, the working pressure drop of this fluidized bed should be in the range from 11000 to $13000 \mathrm{~Pa}$. The air volume flow rate which is measured for normal atmospheric conditions based on a pressure of one bar and air temperature of $\mathrm{T}_{1}=20^{\circ} \mathrm{C}$ is about $\mathrm{V}_{1}=7100 \mathrm{Nm}^{3} / \mathrm{h}$. After being preheated to air temperature of $\mathrm{T}_{2}=$ $850^{\circ} \mathrm{C}$, the air volume flow rate is calculated based on the ideal gas law and Charles's law [32], in which the volume flow rate of gas at constant pressure increases by the same factor as its temperature $\dot{V}_{1} / T_{1}=\dot{V}_{2} / T_{2}$, and therefore is $\dot{V}_{2}=27202$ $\mathrm{Nm}^{3} / \mathrm{h}$, which corresponds to $\mathrm{Q}=7.556 \mathrm{Nm}^{3} / \mathrm{s}$.

The combustion air velocity introduced to the furnace can be calculated using $U_{0}=Q / A$ and $\rho_{g}=m / v$, where $\mathrm{Q}$ denote the volume air flow rate in $\mathrm{m}^{3} / \mathrm{s}$ and $\mathrm{A}=9.3 \mathrm{~m}^{2}$ the distributor plate of the used industrial-scale bubbling fluidized furnace. Thus, with a gas density of $\rho_{g}=0.3105$ $\mathrm{kg} / \mathrm{m}^{3}$ at $850{ }^{\circ} \mathrm{C}$, the fluidization air velocity is 0.81 $\mathrm{m} / \mathrm{s}$. 


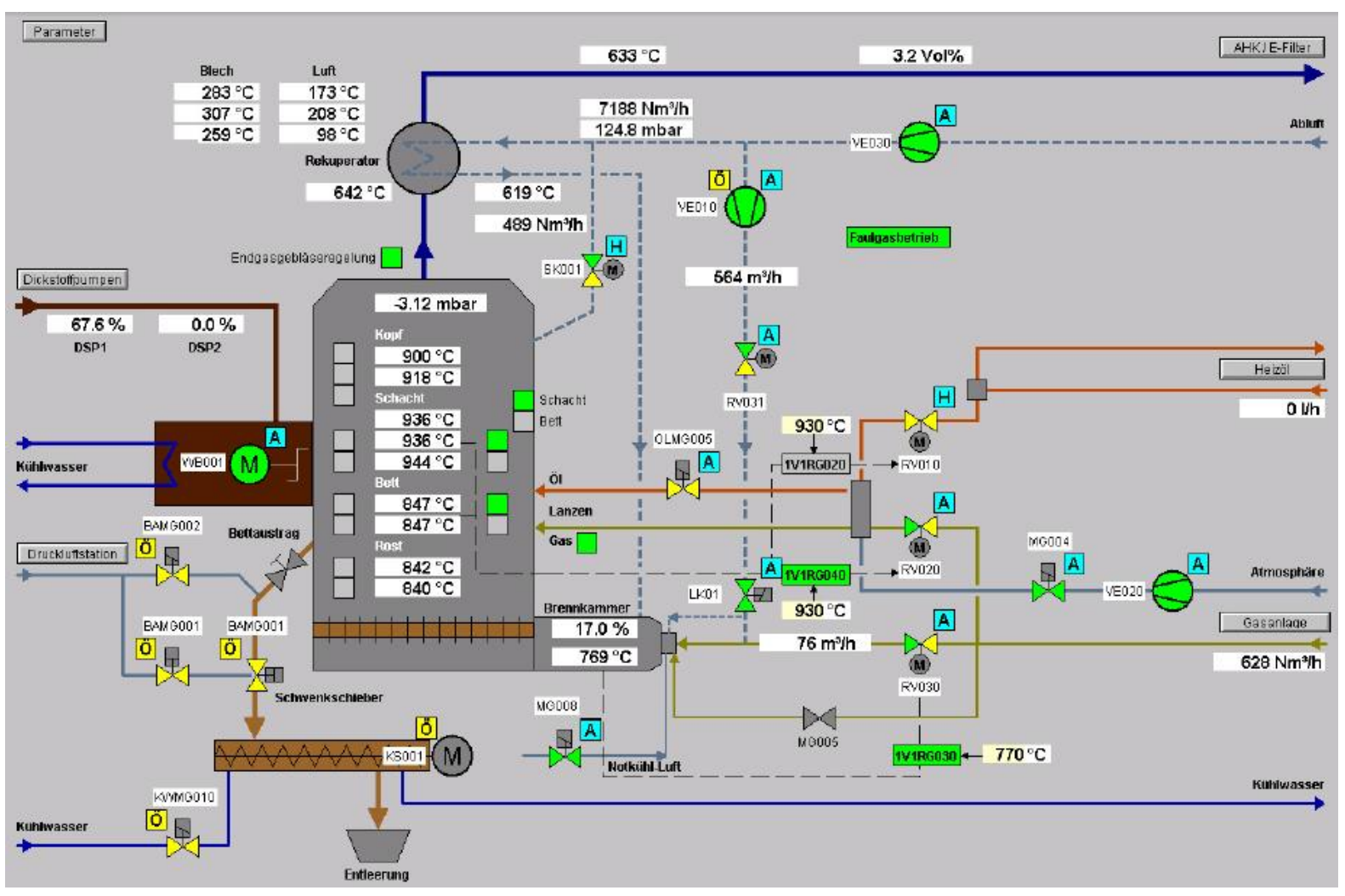

Fig. 2: Screen capture of the bubbling fluidized bed incinerator user-interface in PCS-7 Siemens control system.

\section{RESULTS AND DISCUSSION}

The efficiency of the industrial-scale bubbling fluidized bed combustor is highly dependent on the flow conditions of the inert material inside the furnace. The combustion efficiency of this industrial-scale rig can be improved by providing a stable and uniform fluidization of the inert material inside the bed. The fluidization of bed material is controlled by the combustion air flow rate and monitored by measuring the pressure drop across the bed. Therefore, knowledge about the pressure drop of bed material across the distributor plate and minimum fluidization gas velocity are required to ensure a stable and uniform operation of the industrial-scale rig. In this work the two basic operating parameters that affect the hydrodynamics of the gas-solid flow and the combustion process in the bubbling fluidized beds, which are the minimum fluidization gas velocity and the pressure drop of the inert material have been investigated. The flow behaviour of inert material with a uniform air distribution inside the industrial-scale furnace has been studied experimentally and computationally. The objective of these investigations is to study how the superficial air velocity and particle sizes influence the pressure drop of the bed across the distributor plate of the used industrial-scale rig based on a computational model and simulation approach. The experimental measurements are used to evaluate the accuracy of the simulation results predicted from the CFD model. Quartz sand with three different diameters of $0.5 \mathrm{~mm}, 1.0 \mathrm{~mm}$ and $1.5 \mathrm{~mm}$, with a density of 2650 $\mathrm{kg} / \mathrm{m} 3$ is used as inert material. The momentum exchange coefficients between the gas phase and solid particles were described by the Syamlal and O'Brien drag model equations. Many simulations have been carried out by varying the fluidization air velocity from $0.8 \mathrm{~m} / \mathrm{s}$ to $1.5 \mathrm{~m} / \mathrm{s}$ and sand particle sizes from $0.5 \mathrm{~mm}$ to $1.5 \mathrm{~mm}$ in diameter to provide pressure drop values in the operating range of the used industrial-scale sewage sludge furnace.

Figure 3 shows the predicted pressure drops from the CFD simulations for lower particle sizes with $0.5 \mathrm{~mm}$ in diameter by varying the air velocity from $0.8 \mathrm{~m} / \mathrm{s}$ to $1.5 \mathrm{~m} / \mathrm{s}$. All predicted simulation results of pressure drop are between 11000 to 13000 $\mathrm{Pa}$, and thus in the operating range of the used bubbling fluidized bed. It is shown from the plot that the pressure drop has achieved its maximum value of about $12300 \mathrm{~Pa}$ at fluidization air velocity of 0.8 $\mathrm{m} / \mathrm{s}$. The air velocity at which the maximum value of the pressure drop is achieved is called the minimum fluidization air velocity. It is also shown that by further increasing of the air velocity above the minimum fluidization air velocity to $1.0 \mathrm{~m} / \mathrm{s}$, $1.35 \mathrm{~m} / \mathrm{s}$ and $1.5 \mathrm{~m} / \mathrm{s}$, the obtained pressure drop values of the bed material across the distributor plate have been decreased. The decrease in bed pressure 
drop by increasing the air velocity is caused by the increase in void fraction inside the furnace.

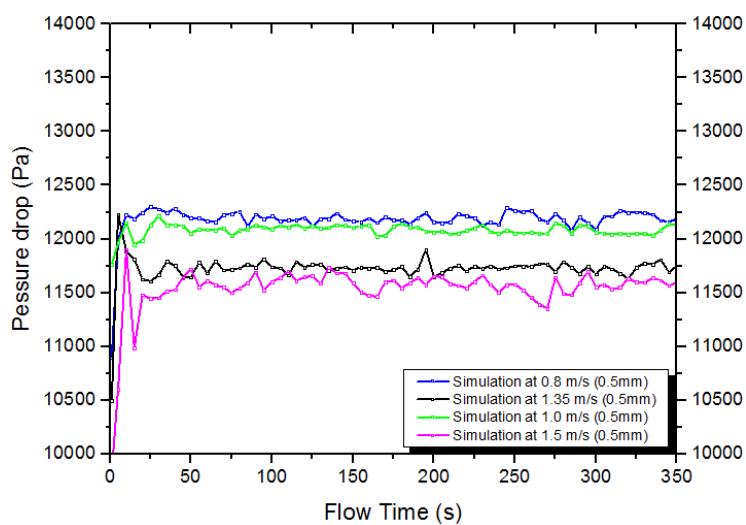

Fig. 3: Time series of pressure drop across the distributor plate of lower particle sizes with a mean diameter of $0.5 \mathrm{~mm}$ by varying the fluidization air velocity

It is also observed that the uniform distribution of the inert material across the distributor plate is provided at a fluidization air velocity of $1.0 \mathrm{~m} / \mathrm{s}$. At this air velocity, the curve of the pressure drop results is approximately linear for the whole simulation time, and therefore the stable fluidization behaviour is achieved. Furthermore, a bubbling fluidization regime of inert material at fluidization air velocity of $1.35 \mathrm{~m} / \mathrm{s}$, and an unstable fluidization regime resulting in large pressure fluctuations at gas velocity of $1.5 \mathrm{~m} / \mathrm{s}$ have been observed.

Figure 4 shows the predicted bed pressure drop curves from the CFD simulations generated by the developed numerical model using sand particles with $0.5 \mathrm{~mm}$ in diameter at four different superficial gas velocities of $0.8 \mathrm{~m} / \mathrm{s}, 1.0 \mathrm{~m} / \mathrm{s}, 1.35 \mathrm{~m} / \mathrm{s}$ and 1.5 $\mathrm{m} / \mathrm{s}$ validated with the experimental measured data obtained from the industrial-scale bubbling fluidized bed. Each simulation of the 3D industrial-scale bubbling fluidized bed was run for 350 seconds. The combustion air velocity of the industrial-scale furnace is approximately $0.8 \mathrm{~m} / \mathrm{s}$. The same value is obtained from the CFD simulation using sand particles with $0.5 \mathrm{~mm}$ in diameter. It can be observed that there is no significant difference between the obtained pressure drops for the both fluidization air velocities $0.8 \mathrm{~m} / \mathrm{s}$ and $1.0 \mathrm{~m} / \mathrm{s}$, and the simulation results and experimental measurements are very close to each other all the time. Higher superficial gas velocity results in high fluctuations of pressure drop of inert material inside the industrial-scale rig.

The fluctuations in pressure drop cause instability and result in slugging fluidization regime. The reason might be due to coalescence of small bubbles, high gas velocity and relatively small particles size. Bed material instabilities lead to nonuniform temperature distribution and to an incomplete combustion of sewage sludge inside the furnace, and thus lead to the formation of flue gas emissions.

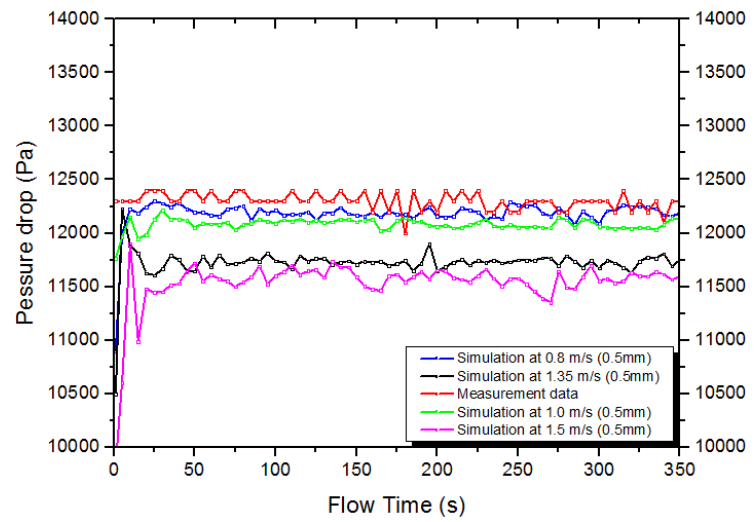

Fig. 4: the comparison of experimental measured data and CFD simulation obtained results of pressure drops using sand particles with $0.5 \mathrm{~mm}$ in diameter at different air velocities

In order to insure that the bubbling fluidized bed combustor operates below a rate where slugging regime occurs, the gas flow rate has been limited to the superficial velocity of $1.35 \mathrm{~m} / \mathrm{s}$. The hydrodynamic behaviour of three different particles at nearly the same superficial gas velocity of about $1.35 \mathrm{~m} / \mathrm{s}$ in the industrial-scale bubbling fluidized bed combustor is investigated by plotting the contours of static pressure drop across the distributor plate and the volume fraction of the solid particles for a simulation time of 300 seconds.

Figure 5 shows the effect of varying particle diameters on the generated pressure drop of the rig.

It is observed that the pressure drop of inert material increases with the increase of solid particle sizes. Generally, it can be noted that the increase in particle sizes results in increasing the pressure drop across the distributor plate of the rig. This could be due to the fact that smaller particles have less drag force compared to the larger particles. Therefore, reducing the solid particle sizes results in a higher degree of expansion which leads to a high impact on fluidization behaviour.

The contours of solid particles volume fraction based on the Syamlal and O'Brien drag model using the same operating conditions as by the industrial-scale bubbling fluidized bed is shown in Figure 6.

The obtained results of sand particles volume fraction with $1.5 \mathrm{~mm}$ in diameter show a uniform particle distribution across the distributor plate and a stable fluidization of the inert material inside the bed, and thus an optimum fluidization 
condition of sand particles is achieved. Non-uniform fluidization with large bubbling and also higher pressure fluctuation were observed for both sand particles with $0.5 \mathrm{~mm}$ and $1.0 \mathrm{~mm}$ in diameter at the same superficial air velocity of about $1.35 \mathrm{~m} / \mathrm{s}$. The contours of the solid particles volume fraction show

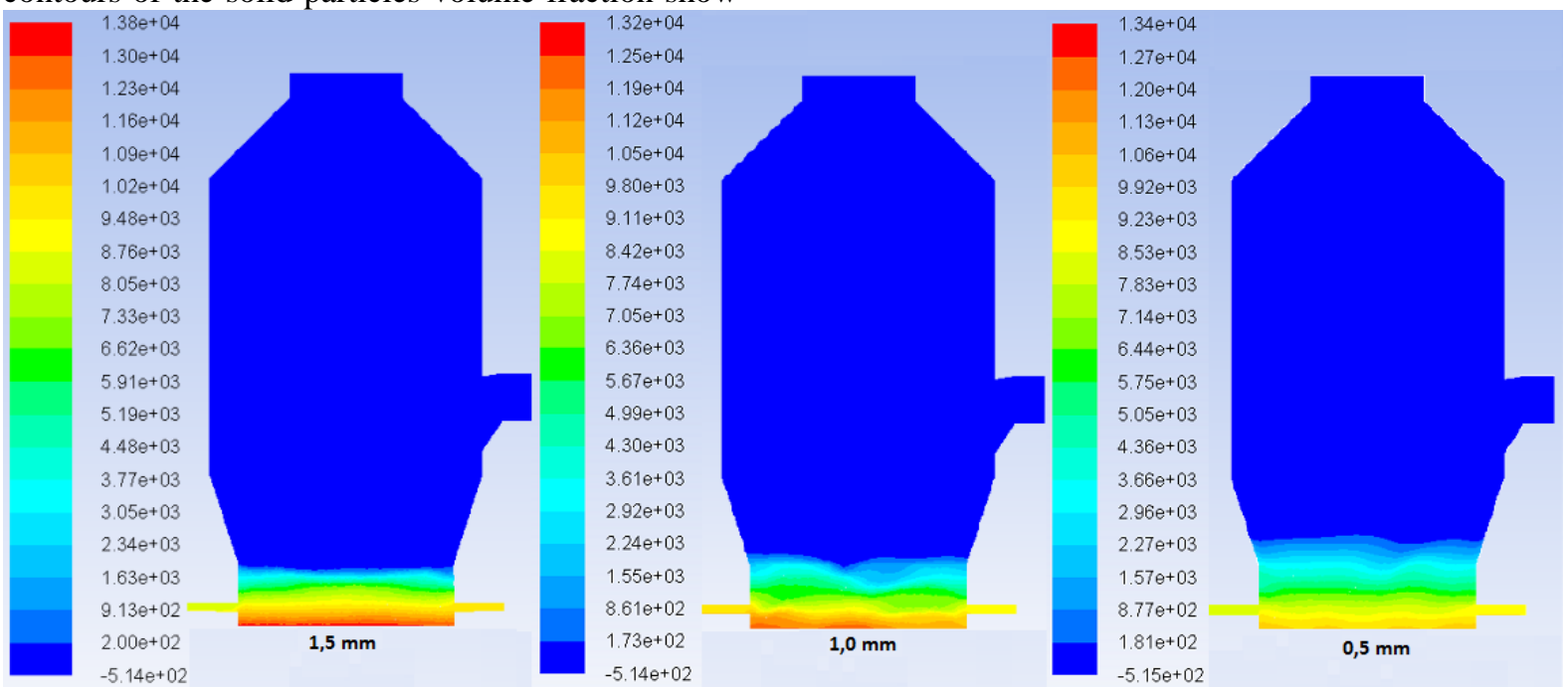

Fig. 5: The static pressure drop of inert material for three sand particle sizes with a mean diameter of $0.5 \mathrm{~mm}$, $1.0 \mathrm{~mm}$ and $1.5 \mathrm{~mm}$ at an average inlet gas velocity of $1.35 \mathrm{~m} / \mathrm{s}$ based on the Syamlal and O'Brien drag model.

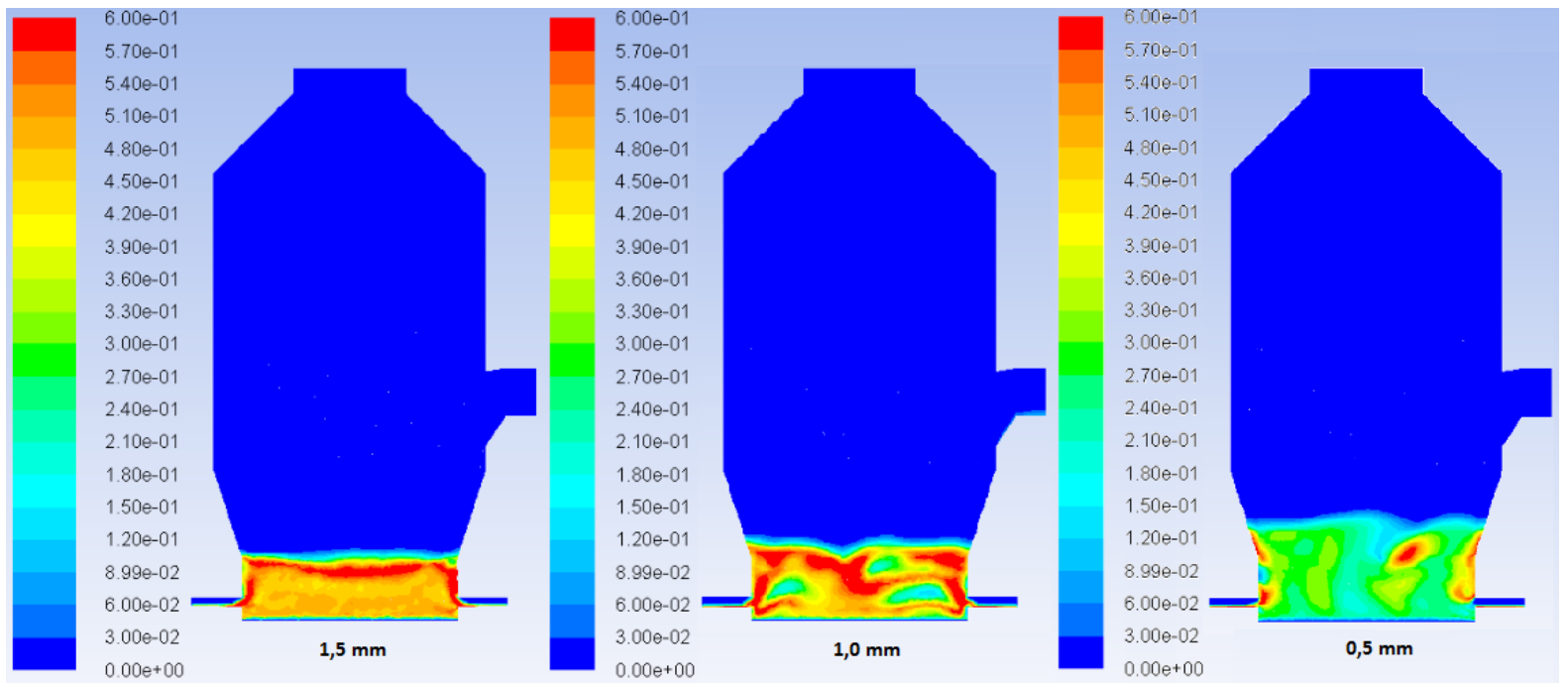

Fig. 6: The volume fraction of solid particles for three sand particle sizes with a mean diameter of $0.5 \mathrm{~mm}, 1.0$ $\mathrm{mm}$ and $1.5 \mathrm{~mm}$ at an average inlet gas velocity of $1.35 \mathrm{~m} / \mathrm{s}$ based on the Syamlal and O'Brien drag model.

Figure 7 demonstrate the achieved pressure drop results from the CFD numerical simulations used in the developed 3D bubbling fluidized bed for three different sand particle sizes at fluidization air velocity of $1.35 \mathrm{~m} / \mathrm{s}$.

All predicted simulation results of pressure drop are approximately between 11500 and 12200 $\mathrm{Pa}$, and thus also here in the operating range of the used bubbling fluidized bed of 11000 to $13000 \mathrm{~Pa}$. It is found that the larger sand particles require much pressure force for the fluidization as lower sand also that the bubble diameter increase with reducing the sand particle sizes, resulting in different sand flow regimes. Slugging regime is observed for particles with $0.5 \mathrm{~mm}$ in diameter due to coalescence of bubbles at higher air velocities. 
observed that the predicted pressure drop increases from approximately 11500 to $12500 \mathrm{~Pa}$ by increasing the sand particle size from 0.5 to $1.5 \mathrm{~m} / \mathrm{s}$, and therefore the minimum fluidization air velocity needed to fluidize the inert material inside the bed increases with the increase in particle size.

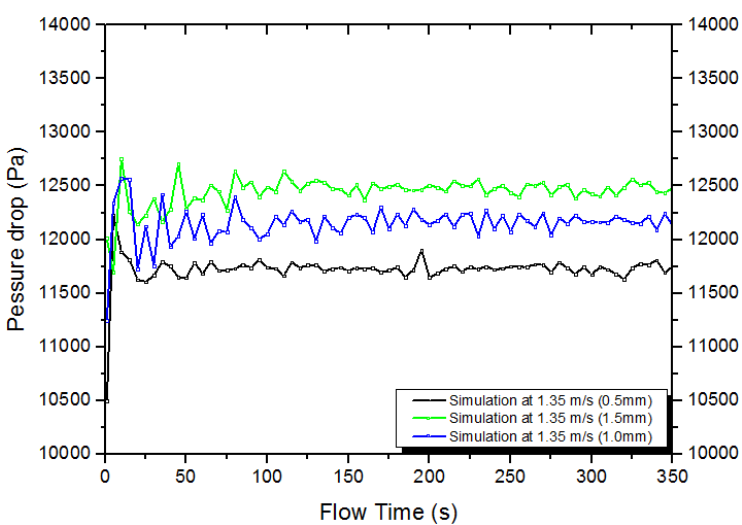

Fig. 7: The effect of sand particle sizes with $0.5 \mathrm{~mm}$, $1.0 \mathrm{~mm}$ and $1.5 \mathrm{~mm}$ in diameter on pressure drops result at a fluidization air velocity of $1.35 \mathrm{~m} / \mathrm{s}$.

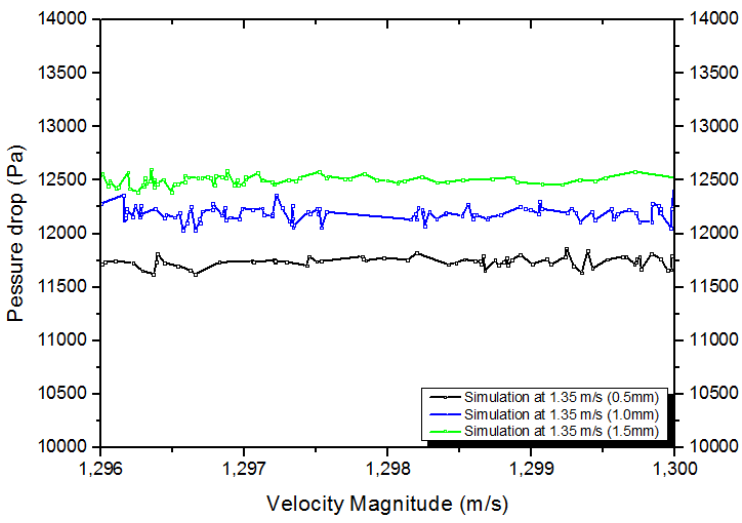

Fig. 8: the pressure drop results against the fluidization air velocity of $1.35 \mathrm{~m} / \mathrm{s}$ for three different sand particle sizes with $0.5 \mathrm{~mm}, 1.0 \mathrm{~mm}$ and $1.5 \mathrm{~mm}$ in diameter.

The comparison of the pressure drop results obtained from the CFD numerical simulations using three different particle sizes of $0.5 \mathrm{~mm}, 1.0 \mathrm{~mm}$ and $1.5 \mathrm{~mm}$ in diameter at a fluidization air velocity of $1.35 \mathrm{~m} / \mathrm{s}$ with the experimental measurements of the furnace is shown in figure 9.

All the predicted numerical results from the developed model were simulated for 350 seconds and validated using the experimental measurements of the industrial-scale rig. As observed from this figure, the simulation results of the inert material with particle sizes of $1.0 \mathrm{~mm}$ and $1.5 \mathrm{~mm}$ in diameter are both consistent with the experimental measurements of the used furnace. For particle sizes with mean diameter of $0.5 \mathrm{~mm}$ at the fluidization air velocity of $0.8 \mathrm{~m} / \mathrm{s}$, both the experimental measured data and the CFD numerical simulation have approximately the same bed pressure drops.

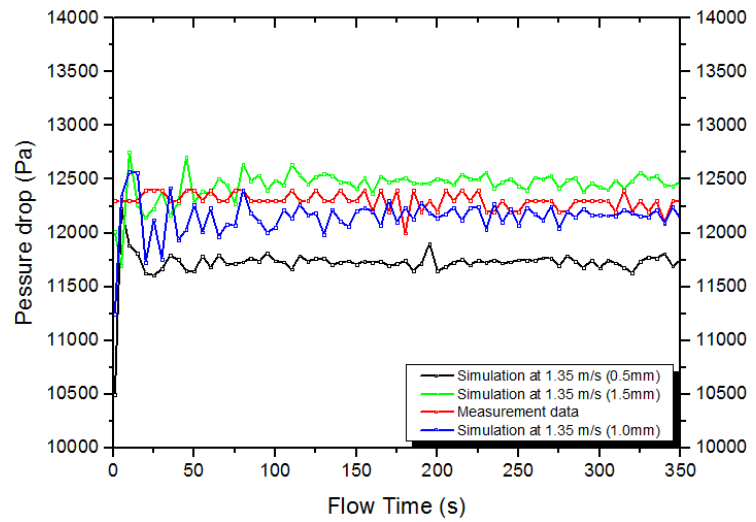

Fig. 9: The comparison of the experimental measurements and numerical simulation results of pressure drops obtained from three different sand particle sizes at superficial air velocity of $1.35 \mathrm{~m} / \mathrm{s}$.

Therefore, the predicted bed pressure drop results from the numerical simulations were relatively close to the experimental measured data. From the predicted CFD numerical results, it is clearly observed that the Syamlal and O'Brien drag model predicts reasonable hydrodynamics of gassolid fluidized beds in terms of pressure drop, and thus correctly predicts the fluidization conditions.

\section{CONCLUSION}

Based on the Eulerian-Eulerian method, the commercial Computational Fluid Dynamics code FLUENT 14.5 is applied to numerically simulate the gas-solid hydrodynamics in a three-dimensional industrial-scale sewage sludge bubbling fluidized bed. The momentum exchange coefficients between the gas phase and solid particles were described by the Syamlal and O'Brien drag model functions. The complex geometry of the developed numerical model represents the actual industrial-scale furnace. The same operating conditions have been applied for both experimental and numerical studies, with varying only the inlet gas velocity and sand particle sizes. To estimate the prediction quality of the developed numerical model, the minimum fluidization air velocity and pressure drop results obtained from the CFD simulations are validated with the experimental measurements. Both CFD numerical simulations and experimental measurements were run for 350 seconds.

The objective of this combined numerical and experimental investigations was, to analyse how sand particle sizes with $0.5 \mathrm{~mm}, 1.0 \mathrm{~mm}$ and $1.5 \mathrm{~mm}$ in diameter and the superficial inlet air velocity from $0.8 \mathrm{~m} / \mathrm{s}$ to $1.5 \mathrm{~m} / \mathrm{s}$ influence the fluidization behaviour of the industrial-scale rig, particularly the generated pressure drop across the distributor plate, 
and finally to determine the efficient parameters for the bubbling flow regime inside the bed. It is found from these numerical investigations that the increase in sand particle sizes results in an increasing of pressure drops across the distributor plate of the furnace. It is also observed that the expansion of inert material inside the bed increases with the increase of the fluidization air velocity and the decrease of quartz sand particle sizes. A nonuniform fluidization with a large pressure drop fluctuations of bed material for smaller particle size with a mean diameter of $0.5 \mathrm{~mm}$ at higher fluidization air velocity of $1.5 \mathrm{~m} / \mathrm{s}$ resulting in slugging regime have been observed. Therefore, to prevent this pressure drop fluctuations which can cause temperature non-uniformity in the industrialscale bubbling fluidized bed combustor, the inlet air velocity introduced to the furnace has been limited to a superficial velocity of $1.35 \mathrm{~m} / \mathrm{s}$. All predicted CFD numerical results of the pressure drop across the distributor plate are in the operating range of the used industrial-scale bubbling fluidized bed furnace of 11000 to $13000 \mathrm{~Pa}$ and approximately identical to the experimental measured data. Based on the generated pressure drops from the developed CFD numerical model and Syamlal and O'Brien model functions, the minimum fluidization air velocity using smaller particle sizes with a mean diameter of $0.5 \mathrm{~mm}$ was discovered to be $0.8 \mathrm{~m} / \mathrm{s}$. This air velocity is approximately identical to the operating air velocity of the used industrial-scale bubbling fluidized bed, and thus similar to the experimental measurements. Therefore, the CFD model proposed in this work was found in general to provide a good pressure drop predictions at a wide range of fluidization air velocities and also for different quartz sand particles and to agree well with the experimental measured data of the used industrialscale combustor. These CFD numerical simulations indicate that the Syamlal and O'Brien drag model functions are able to successfully forecast the hydrodynamics of gas-solid flow in this industrialscale bubbling fluidized bed combustor, and thus the developed CFD model provides detailed informations for further work on control strategies of the combustion process. The CFD numerical investigations need high computer resources, especially for three-dimensional models of industrial-scale fluidized beds.

\section{REFERENCES}

[1] Deutsche Vereinigung für Wasserwirtschaft, Abwasser und Abfall e.V. Hennef: Thermische Behandlung von Klärschlämmen: Monoverbrennung (DWAM 386, 2011).

[2] Wiechmann, B., Dienemann, C., Dr. Kabbe, C., Brandt, S., Dr. Vogel, I. und Dr. Roskosch,
A.: Sewage sludge management in Germany (Umweltbundesamt, 2013).

[3] Sahoo, P. and Sahoo, A.: A Comparative Study on Fluidization Characteristics of Coarse and Fine Particles in a Gas-Solid Fluidized Bed. CFD Analysis, International Journal of Engineering Science and Innovative Technology. (3), 2014, 246-252.

[4] Benzarti, S., Mhiri, H., Bournot, H.: Drag models for Simulation Gas-Solid Flow in the Bubbling Fluidized Bed of FCC Particles. World Academy of Science, Engineering and Technology, (6), 2012, 980-985.

[5] Herzog, N., Schreiber, M., Egbers, C. and Krautz, J. H.: A comparative study of different CFD-codes for numerical simulation of gassolid fluidized bed hydrodynamics, Computers and Chemical Engineering, (39), 2012, 41-46.

[6] Lundberg, Joachim: CFD Study of A Bubbling Fluidized Bed, Master thesis, Telemark University College Norway, 2008.

[7] Armstrong, Lindsay-Marie: CFD modelling of the gas-solid flow dynamics and thermal conversion processes in fluidized beds, $\mathrm{PhD}$ thesis, University of Southampton, 2011.

[8] Vejahati, F., Mahinpey, N., Ellis, N. and Nikoo, M. B.: CFD Simulation of Gas-Solid Bubbling Fluidized Bed, A New Method for Adjusting Drag Law, The Canadian Journal for Chemical Engineering, (87), 2009, 19-30.

[9] Taghipour, F., Ellis, N. and Wong, C.: Experimental and computational study of gassolid fluidized bed hydrodynamics, Chemical Engineering Science, (6), 2005, 6857-6867.

[10] Hamzehei, Mahdi: CFD Modelling and Simulation of Hydrodynamics in a Fluidized Bed Dryer with Experimental Validation. ISRN Mechanical Engineering, 2011, Doi: 10.5402/2011/131087

[11] Belhadj, E., Chilton, S., Nimmo, N., Roth, H. and Pourkashanian, M.: Numerical simulation and experimental validation of the hydrodynamics in a $350 \mathrm{~kW}$ bubbling fluidized bed combustor. International Journal of Energy and Environmental Engineering. (7), 2016, 27-35. DOI: 10.1007/s40095-015-0199-4

[12] Hamzehei, Mahdi: Study of Heat Transfer in the Poly Ethylene Fluidized Bed Reactor Numerically and Experimentally. World Academy of Science, Engineering and Technology, 5(6), 2011, 1076-1084.

[13] Hamzehei, Mahdi: Study of Hydrodynamics and Heat Transfer in the Fluidized Bed Reactors. Heat Transfer-Mathematical Modelling, Numerical Methods and Information Technology, chapter 14. InTech Publication, 2011. 
[14] Hamzehei, M. and Rahimzadeh, H.: Study of Parameters Effect on Hydrodynamics of a Gas-Solid Chamber Experimentally and Numerically, EPJ Web of Conferences, (25), 2012. Doi: 10.1051/epjconf/ 20122502005

[15] Ramesh, P. L. N. and Raajenthiren, M.: A Review of some existing drag models describing the interaction between the solidgaseous phases in a CFB. International Journal of Engineering Science and Technology, 2(5), 2010, 1047-1051.

[16] Almuttahar, Adnan M.: CFD modeling of the hydrodynamics of circulating fluidized bed riser, Master thesis, The University of British Columbia, 2006.

[17] Esmaili, E., Mahinpey, N.: Adjustment of Drag Coefficient Correlations in Three Dimensional CFD Simulation of Gas-Solid Bubbling Fluidized Bed, Advances in Engineering Software. 42(6), 2011, 375-386.

[18] Lu, B., Wang, W., Li, J., Wang, X., Gao, S., Lu, W., Xu, Y., Long, J.: Multi-scale CFD simulation of gas-solid flow in MIP reactors with a structure dependent drag model, Chemical Engineering Science, (62), 2007, 5487-5494.

[19] Schreiber, M., Asegehegn, T. W. and Krautz, H. J.: Numerical and Experimental Investigation of Bubbling Gas-Solid Fluidized Beds with Dense Immersed Tube Bundles, Industrial and Engineering Chemistry Research, (50), 2008, 7653-7666.

[20] Sun, J., Zhou, Y., Ren, C., Wang, J., Yang, Y.: CFD simulation and experiments of dynamic parameters in gas-solid fluidized bed, Chemical Engineering Science, (66), 2011, 4972-4982.

[21] Azadi, Mehdi: Multi-fluid Eulerian modelling of limestone particles elutriation from a binary mixture in a gas-solid fluidized bed, Journal of Industrial and Engineering Chemistry, (17), 2011, 229-236.

[22] Fan, Rong: Computational fluid dynamics simulation on fluidized bed polymerization reactors, $\mathrm{PhD}$ thesis, Iowa State University, 2006.

[23] Asegehegn, T. W., Schreiber, M., Krautz, H. J.: Numerical Simulation of Dense Gas-Solid Multiphase Flows using Eulerian-Eulerian Two-Fluid Model, Edited by Zhu J. Computational Simulations and Applications (InTech Rijeka, Croatia, 2011).

[24] England, Jonas A.: Numerical Modelling and Prediction of Bubbling Fluidized Beds, Master thesis, Virginia Poly Technique Institute and State University, 2011.

[25] Abrha, Tigabu: Design and Development of Fast Pyrolysis Fluidized Bed Reactor for Bio- oil Production, Master thesis, Addis Ababa University, 2011.

[26] Rangelova, Janitza: Auftriebsverhalten von Feststoffpartikeln in Wirbelschichten, $\mathrm{PhD}$ thesis, Otto von Guericke University of Magdeburg, 2002.

[27] Sobrino Fernandez, Celia: Experimental study of a bubbling fluidized bed with a rotating distributor, $\mathrm{PhD}$ thesis, Carlos III University of Madrid, 2012.

[28] Karmakar, M. K., Haldar, S. and Chatterjee, P. K.: Studies on fluidization behaviour of sand and biomass mixtures, International Journal of Emerging Technology and Advanced Engineering, (3), 2013, xxx-xxx.

[29] Prabir Basu: Combustion and Gasification in Fluidized Beds (Taylor and Francis. USA, 2006).

[30] Teaters, Lindsey: A Computational Study of the Hydrodynamics of Gas-Solid Fluidized Beds, Master thesis, Virginia Poly Technique Institute and State University, 2012.

[31] Passos, M. L., Barrozo, M. A. and Mujumdar, A. S.: Fluidization Engineering Practice (Laval Canada, 2013).

[32] Job, G.; Rüffler, R.: Physikalische ChemieEine Einführung nach neuem Konzept mit zahlreichen Experimenten, 1. Auflage (Vieweg + Teubner, Wiesbaden, 2011). 